\author{
Martínez Barragán Carlos. \\ Profesor COD, Universidad Politécnica de Valencia, Departamento de Dibujo, grupo de investigación \\ de Creaciones Intermedia.
}

\title{
Cualidades hápticas de la imagen digital.
}

\author{
TIPO DE TRABAJO
}

Comunicación.

PALABRAS CLAVE.

Háptico, imagen digital, mimesis perceptual.

KEY WORDS

Haptic. Digital Image, Perceptual Mimesis.

RESUMEN

Gran parte de las cualidades de la imagen digital se generan a partir de imitar las cualidades texturales de la imagen perceptual, lo que lleva a los creadores de softwares a recurrir a la historia de la imagen (fotografía, pintura, dibujo, grabado, fotografía) para aumentar las posibilidades de manipulación de las imágenes ya que en esta historia se encuentran muchos logros que han alcanzado una identificación táctil entre la imagen y su representación. La imagen digital, en sus diversas formas de producción y visualización, es la que, supuestamente, se dirige a la visualidad "pura" por propia naturaleza. Sin embargo, el desarrollo de las diferentes aplicaciones y las maneras en las que ésta se visualiza nos dicen lo contrario. Es cierto que no todas las imágenes digitales recurren de la misma forma y en el mismo grado a este tipo de procedimientos plásticos, pero en el momento en que se hacen visuales surge la relación háptica entre imagen y percepción. No es posible generar la imagen puramente visual, ya que en la percepción se encuentran inmersas una serie compleja de relaciones sensoriales que en diferentes grados implican la sensación táctil de la imagen. La verisimilitud descansa en un alto grado en la percepción de las cualidades táctiles de la imagen, lo que denomino mímesis perceptual. Las animaciones digitales creadas por el cine y los juegos hiperrealistas son un ejemplo de ello. Si nos asombra su verisimilitud es porque sentimos las microestructuras de las imágenes casi de la misma forma en que las percibimos en la realidad (también la realidad creada por la historia de la imagen). Podríamos decir con Plinio: "También se dice que Zeuxis pintó más de un niño...: "pinté mejor las uvas que el niño, si lo hubiera hecho tan bien, el pájaro hubiera tenido miedo".

\section{ABSTRACT}

The qualities of the digital imagen is generated from imitate the textural qualities of perceptual image, leading software creators to turn to history image (photography, painting, drawing, printmaking, photography) to increase the potential for manipulation of the images because in this story are many examples that this relationship between the tactile identification of the image and its representation. Digital imagen, in its various forms of production and display, supposedly goes to the "pure" visuality. However, the development of the applications and the ways in which it is displayed tell us otherwise. It is true that not all digital images used in the same ways and to the same degree the plastic processes, but at the time they are made visual, the haptic relationship between image and perception turn up. Unable to generate the purely visual image because the perception are complex series of sensitive relationships that involve varying degrees tactile image. Verisimilitude rests to on the perception of the tactile qualities of the image, what I call perceptual mimesis. Digital animations created for the cinema and hyperrealistic games are a example for this. If your verisimilitude astonish us is because we feel the microstructures of imagery in much the same way that we perceive in reality (also the reality created by the history of the image). We could say with Pliny: "It is also said that Zeuxis painted over a child ..." I painted the grapes better than the child, if he had done so well, the bird had been afraid." 


\section{CONTENIDO}

1. La distancia entre objeto y captura del índice lumínico en la fotografía.

1.1. La imagen latente.

1.2. La imagen transcodificada.

2. La mímesis perceptual.

2.1 La mímesis percetual. Lo háptico como función necesaria.

2.2 La pantalla como individuo y la pantalla como imagen.

Estamos inundados de imágenes evanescentes por lo cambiantes. El mundo de las imágenes digitales lleva una velocidad de vértigo. Y no sólo cuando la pantalla es su medio de distribución y consumo, que en este caso es inseparable e indiferenciable; sino en la imagen impresa ya que la cantidad de estas imágenes superan cualquier tipo de estimación. Es así, imágenes por todos lados, en muchos soportes, con intenciones disímiles, produciéndose más y más y cada vez más. Esto ha llevado a que la imagen esté teniendo una atención extraordinaria de la industria, la ciencia y las artes. Esta atención, que es ahora difícil de determinar si es exagerada o no, produce un número ingente de escritos y ensayos de todas las ramas del conocimiento, además de la producción masiva de imágenes realizadas por toda la población que tiene acceso a la tecnología ya sin importar si están vinculados profesionalmente al mundo de la imagen. La industria que fabrica los medios tecnológicos han abaratado los costes de producción y han inundado a la población de cámaras digitales que hacen fotos y videos con suma facilidad y que subidos a la red generan esa enormidad de imágenes que circulan permanentemente de forma inmaterial.

\section{La distancia entre objeto y captura del índice lumínico en la fotografía.}

La fotografía inicia esta era de la superproducción de imagen. Aunque en sí misma, la fotografía no nace como proceso de reproductibildad del objeto-imagen, si nace con algunos elementos característicos de las nuevas tecnologías. El más llamativo, por su repercusiones directas en su contexto, fue la automatización en la realización. Esto llevó a la suplantación de procesos manuales sencillos, como dibujar y pintar, y a la sustitución de herramientas sencillas, como el pincel o el lápiz, por unas más complejas y sofisticadas, como la óptica, los mecanismos de obturación y los soportes y materiales químicos para el revelado y la fijación de la imagen. Este cambio, y aquí trataré de no referirme al cambio ontológico que supuso a la idea de "arte", inmediatamente supuso que el registro de la huella de los materiales y los procesos se transformaran en un modo nuevo de registro de la huella. De la huella manual, se pasa a la huella de lo visto, lo que origina esta focalización hacia la mirada, que es la que más adelante, justificará a la fotografía como arte y que aún hoy sigue siendo una de las diferencias cualitativas entre fotografía y los demás medios manuales.

"Imaginemos que el espectador pudiera mirar sin verbalizar, pudiera ver sin (incluso silenciosamente, internamente) Subvocalizar asociaciones, juicios y observaciones. ¿Qué quedaría? Bien, una cosa que evidentemente quedaría es la observación de que una pintura es un objeto hecho a mano, y esto es una de las características cruciales que lo diferencia, por ejemplo de la fotografía, en que el aspecto de producción mecánica tan a menudo pasa a primer plano." (Mitchell. 2005. p. 19)

Manovich habla del automatismo como una de los elementos que han configurado los "nuevos medios". (Manovich, 2005. p. 66). Según él, la codificación numérica y la estructura modular de los objetos digitales es lo que ha desplazado el registro de la manualidad (lo describe como <<intencionalidad humana del proceso creativo>>. (Manovich, 2005. p. 77). ) hacia el registro de la mirada, en este caso proyectada en el uso de la computadora y el software utilizado. En la fotografía analógica no se incluyen estas dos etapas de manera tan directa, por lo que el automatismo aquí reside en otro lado. La mirada está representada por la óptica de la cámara; el ojo tiene su sustituto adecuado, que no permite interferencias entre él y la realidad, so pena de desvirtuar el acto perceptual de ver y con él, una idea completamente moderna de el empirismo como base fundamental del conocimiento y la verdad.

Con la fotografía, ver significó apresar, agarrar, tomar, coger, tocar. Con la pintura la realidad no se apresaba, se construía. Lo que hacía que la función táctil estuviera ya contenida en el acto de construir. (Esta relación indisoluble entre el construir y el tocar en pintura, hace que sea este uno de los aspecto más importantes a la hora de verificar la autenticidad de una pintura). En fotografía la construcción está delegada a un proceso técnico más sofisticado, en donde la manualidad se reduce a unas cuantas operaciones mecánicas que no necesitan de una gran especialización. La química hace el resto. Es posible hacer aquí la introducción de la "codificación numérica" mencionada más arriba, en las reacciones químicas, aunque las variables son tan grandes que una codificación de esto resulta contraproducente para la creación de la estructura modular y posteriormente de la misma automatización. Y sin embargo, este proceso de automatización llegó a buen puerto cuando la industria fotográfica creó las máquinas de revelado y ampliación automáticas que llenaban las tiendas de fotografía en los años noventa. Fotografiar significaba escindir el tiempo y el espacio. De aquí esa "tautología" que le adjudica Fontcuberta a la foto analógica en relación con la memoria y la creación de documentos y que con la fotografía digital se roto(Fontcuberta, 2010. p. 27).

Lo que trataré de aclarar es que en la pretensión de la representación, tanto manual como automatizada, existe la necesidad de tomar, de tocar, de "manosear", ya que los niveles de tactilidad, de sensibilidad táctil a distancia, siempre están presentes en la 
percepción. Es por ello que una tecnología se dirige hacia un lado y no hacia otro. En el caso de la fotografía, muchos esfuerzos estuvieron dirigidos a que los objetos fotografiados tuviesen una discreción adecuada, adecuada a la manera en que percibimos de manera espontánea la realidad. La microtextura de la fotografía permite que podamos recrear las texturas percibidas espontáneamente y que podamos afirmar de manera háptica espacios, distancias, rugosidades, temperatura, grados de humedad y un montón de información más que vemos-sentimos corporalmente con la fotografía. Si la fotografía fuese un ícono puro, como en algunas ocasiones se ha llegado a plantear, sería simplemente irreconocible por cualquiera de nosotros, o más bien, inmediatamente se incorporaría a nuestra percepción transformando su pureza en grados variables de hapticidad, de tactilidad.

La exigencia de que lo fotografiado tuviese una relación fuerte con la realidad percibida es una cuestión que se ha abordado a lo largo de los estudios filosóficos, estéticos y ahora sicológicos y neurológicos. La mímesis no ya como una construcción conceptual, como una ontología de la representación, sino como una necesidad de la percepción, como una especie de determinismo sicológico y biológico que nos ha impelido desde siempre a representar miméticamente la realidad. Y en este caso hablo de una representación global, que involucra todos los sentidos del cuerpo humano que se dirigen a la mímesis. Esto quiere decir que los grados en los que unos sentidos se involucran en la representación es lo que origina cambios en las imágenes. El contexto por supuesto que aquí juega un papel determinante. Pero lo que sentimos cuando estamos en el mundo, lo buscamos cuando miramos ese mismo mundo.

La fotografía aportó distancia física al registro de la huella, y cambió el actor de ese rastro, en vez de la mano puso al ojo. Y es en esa distancia donde descansan muchos de los argumentos que hablan de la supremacía de lo visual en detrimento de lo táctil. Sin embargo, lo táctil, lo háptico, nunca ha desaparecido, todo lo contrario. Ha estado apoyando la creación de una nueva forma de representación mimética.

"La fotogenia no es una propiedad exclusiva de la realidad, ni es un simple efecto del dispositivo óptico ni resulta de un truco del operador; brota en cambio de una alianza necesariamente a tres partes entre el modelo, la cámara y el fotógrafo. La fotogenia sólo se manifiesta como destello de un poder latente sublimador que no puede ser controlado" (Fontcuberta, 2010. p. 21).

¿Qué es la fotogenia sino una sensación, una constatación de una percepción compleja en diferentes niveles y que se dirige a diferentes partes en diferentes individuos? Lo único que podemos llegar a consensuar es que se siente, se siente con los ojos y se reafirma con todo el cuerpo. La aseveración de que "esta persona es fotogénica" marca una alianza entre cuatro partes, y no tres como dice Fontcuberta. Hace falta que alguien sienta la fotogenia.

\subsection{La imagen latente.}

La codificación, la modularidad, la variabilidad y la automatización son características de los medios digitales. Según el esquema de Manovich falta un paso para la producción de la imagen-pantalla, la imagen que podemos observar como tal. Antes de eso, la latencia es un estado abstracto que hace impenetrable, al menos a través de medios sensoriales, cualquier imagen digital. Es en cierto sentido, lo más próximo al estado de latencia que tenía la fotografía analógica después de la toma y antes del revelado; en ese momento el carrete era sólo un pequeño objeto cilíndrico. En potencia, sin duda, cada una de las características antes mencionadas, se resuelven en la abstracción mental y en ese lugar, ninguna de ellas es realmente importante. Y no es que no existan la imágenes mentales y que éstas no sean también una realidad percibida, pero hasta que no se concretan en un objeto, no es posible generar el acuerdo que nos lleva a hablar sobre las mismas. Lo que quiero señalar aquí no es tanto las diferencias entre latencias fotográficas analógicas y digitales, sino el hecho de que en la concreción de las imágenes hay ya un interés específico para que se objetualicen de una forma y no de otra. La transcodificación de los datos se realiza bajo una serie de objetivos concretos, y éstos han sido construidos para crear imágenes que hagan referencia a nuestra percepción espontánea. Para ello, en muchas ocasiones se utilizan recursos que han demostrado su correcto papel en la representación. Líneas, colores locales, abstracciones bidimensionales que tratan de ilusionarnos con las tres dimensiones, formatos de pantallas, profundidades de campo, etc., etc. son aspectos formales que se implementan en los procesos de transcodificación de los datos digitales. Esa ordenación parecería que responde a una especie de estado de tránsito entre esta cultura digital y nuestro pasado analógico.

Hoy por hoy, los procesos gráficos que han decidido virtualizarse, digitalizando sus medios y sus fuentes visuales, viven todavía atrapados y poseídos por la fascinación que la experiencia háptica ejerce -a través del soporte físico- sobre el individuo propio de una cultura en transición que todavía valora los parámetros sensoriales que le pueden ofrecer los elementos constituyentes de lo materialobjetual. (Alcalá. 2015. p. 62)

Pero creo que responde más bien al estado de prerracional de la mímesis (Sarikartal. 2005.p. 112) que nos compele a encontrar un sitio adecuado para la mejor percepción de la imagen con la cual construimos una correcta gestalt. $Y$ es en esta correcta percepción en donde no es posible dejar fuera a lo táctil que está incluido en el acto mismo de percibir. Es, tal vez, aceptar en gran medida la naturalidad de la mímesis, o en palabras de Aristóteles:

La causa de eso es que aprender es cosa muy agradable no solamente para los filósofos sino también para los demás hombres; sólo que éstos toman parte en él en escasa medida. Se halla, en efecto, agrado en mirar las imágenes porque ocurre que al contemplarlas 
se aprende y se deduce qué es cada cosa; por ejemplo, que éste es aquél. Y si no se ha visto antes, no producirá placer en cuanto imitación, sino por la ejecución, por el color o por alguna otra causa semejante. (Aristóteles. s/f, 2009 p. 24)

No es por una especie de nostalgia por un pasado ilustrado en donde la relación con la materia era una construcción metafísica, un acuerdo estético y una demostración de una verdadera ontología del arte. La prerracionalidad mimética parece acercarse más a la respuesta sobre el por qué de la gran demanda que tienen las soluciones formales miméticas en los videojuegos. La acuciosidad de elementos formales (texturas, colores, iluminaciones, movimientos, brillos, relaciones de tamaño y forma, simulación de la tridimencionalidad, etc.) no sólo responde a un estadio del avance de la tecnología, sino a una dirección que se establece por un consenso perceptual que apunta hacia un desarrollo mimético dirigido con al menos tres diferentes estrategias $<<$ regímenes escópicos >> de Foucault, como medio de documentación y sobre todo, de control y <<vigilancia >> propuesta por Virilio o el <<simulacro >> de Baudrillard. (Mitchell, 2005. p.25).

La transcodificación que se dirige hacia una mímesis perceptual y corpórea ha dejado atrás el concepto aristotélico de la

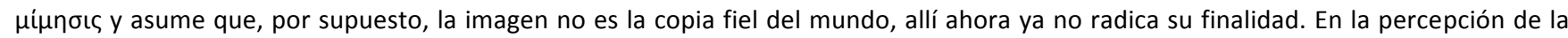
imagen es necesario una confirmación completa del precepto de manera multisensorial lo que hace que la imagen pueda incorporarse al mundo del perceptor. Es así allí hacia donde se dirigen los esfuerzos por transcodificar los datos discriminados de los archivos digitales:

Del mismo modo que en la televisión está ahí pero falta la codificación, en Estática toda la información contenida en el archivo original persiste. En sentido estricto, no ha habido una destrucción, sino una transformación: un reordenamiento (un desordenamiento) de los atributos formales que imposibilitan el acceso al contenido. La información está físicamente allí pero nos resulta ininteligible; ha sido encriptada de tal forma que ya no somos capaces de descifrarla. Como una metáfora de lo que sucede en tantos archivos, los documentos ya no arrojan claridad, sino que nos confunden."(Foncuberta 2010. p. 180)

Por "ininteligible" entiendo que se refiere Fontcuberta a que no es posible percibirla, que no hay reconocimiento ni conocimiento, que está fuera del alcance perceptual, y allí entran en juego los programas que acomodan de cierta forma la información para que seamos capaces de "sentirla", o sea verla, reconocerla, establecerla en un espacio, y en esa medida, hacerla corporal.

\subsection{La imagen transcodificada.}

Los programas de tratamiento digital de la imagen presentan las características de variabilidad, modularidad, discriminación, automatización y transcodificación. Por lo que sus posibilidades de transcodificarse se multiplican enormemente. Sin embargo, están destinados a concretarse en formas visuales. Esa concreción es la que nos permite que lo intangible, perceptualmente hablando, se muestre tangible. Y en ese momento podemos actuar en la imagen accionando las características antes mencionadas. La "tangibilidad" es antes que otra cosa, contacto, poder ser tocado. Ciertamente que la imagen digital concretada en imagen-pantalla se toca con los ojos, se convierte en una tangibilidad con una carga óptica fundamental, pero esto no resta que otros sentidos estén presentes en esa concreción. No es posible tocar con los ojos sin que intervenga una sensación de espacio y con ello, una conciencia del cuerpo. Por ejemplo, Fontcuberta afirma que "lo ontológico de la fotografía se disuelve en la imagen" y que ello conlleva "el descrédito de su proverbial representación naturalista." (Foncuberta 2010, p. 27). Esa disolución no sería posible sin una plena incorporación de la imagen a nuestro mundo tangible. No podríamos disolvernos en una imagen de rayos x sin que esta estuviera "transcodificada" en una placa, aún sabiendo que existe. Si la fotografía se disuelve en la imagen es porque la percepción prerracional mimética nos disuelve a nosotros mismos en la imagen. Formamos parte del espacio de representación que se nos muestra sintiendo que formamos parte de lo que vemos de manera sensorialmente completa. Sin embargo, esta disolución perceptual no es completa identificación, no es que tomemos a la imagen por la realidad. Es que cedemos a la imagen un sitio en nuestro mundo y ya en él podemos llenarla de relaciones sensoriales y significantes. La mímesis es entonces isomorfismo perceptual, esto es, vemos la imagen de la misma forma en que vemos la realidad y adecuamos todos los procesos que la generan a realizar ese isomorfismo. Por ello Fontcuberta afirma que "la fotografía es, antes que espejo, especulación ya que es esencialmente una manipulación más o menos inconciente." (Foncuberta 2010. p. 54) Esa manipulación se hace en base a nuestra necesidad de incorporar la visión a nuestro mundo y no podemos resolver este dilema sin que todos los sentidos, además de todos los procesos significantes estén presentes. Si existe una constatación de lo háptico en la imagen digital es la transcodificación de los datos discretos en imágenes (textos, forma, colores, espacios, texturas) o en sonidos; sin esa tangibilidad, los datos, aunque existentes son realmente la virtud del pensamiento, la virtualidad.

En la actualidad los estudios sobre psicología de la percepción defienden que las distintas modalidades sensoriales no funcionan como elementos independientes, sino que proporcionan información complementaria, convergente en la comprensión de la realidad. La interactividad de los entornos virtuales pone en juego la vista, el oído y la cinestesia táctil en un intento por lograr la máxima integración sensorial de información que proviene de tres espacios: el del propio espectador-actor, el de la realidad física que le envuelve y el de la realidad virtual en la que se le integra. (Hoyas, 2010).

Manovich (2005) , al hablar del áurea que contiene la distancia, apoyándose en Benjamin y Virilio, reafirma que la tecnología y los nuevos medios siguen manteniendo un orden perceptual espontáneo, con ciertas modificaciones, pero que básicamente mantienen 
una referencia con las "tecnologías modernas" porque siguen parámetros preceptúales comunes. Y también señala que la transcodificación, aunque automatizada, se dirige a lo que en este ensayo he denominado como mimetismo perceptual.

La producción de representaciones ilusionistas se ha vuelto el terreno de la cultura de masas y de las tecnologías mediáticas: la fotografía, el cine y el video. La creación de ilusiones se ha delegado en los aparatos ópticos y electrónicos. (Manovich 2005. p. 238). Sólo remarcar que la producción se delega, pero no se delega lo que se produce. Esa responsabilidad sigue siendo del productor de los procesos electrónicos e informáticos que fabrican tanto el hardware como el software.

\section{La mímesis perceptual.}

Manovich (2005) expone que el ilusionismo a guiado a las artes y a la producción de la imagen durante siglos, exceptuando los intentos de las vanguardias del siglo XX. Sin embargo, durante los últimos años del siglo XX y lo que llevamos del XXI presenciamos un resurgimiento de esa dirección hacia el ilusionismo. O como Marchan Fiz argumenta (2005) que de la misma forma que el arte es desplazado por la visualidad, la percepción artística es suplantada por la representación.

Ciertamente que la imagen digital contiene operaciones que no son correspondientes al ilusionismo perceptual, como la lógica de los algoritmos que crean y ordenan los datos discriminados. Pero el esfuerzo que la industria ha realizado para que todos esos datos sean tangibles es para que la imagen se concrete en referencia a las capacidades preceptúales espontáneas. El autor se pregunta si las imágenes dejarán esa referencia perceptual (que identifica con las imágenes cinematográficas), o en sus palabras, la búsqueda de "las mejores imágenes ilusionistas", y crearán unas nuevas que estén en una mayor sintonía con la lógica de los medios digitales. Y responde que no. El argumento que da sobre esa negativa engloba varios conceptos que estoy incluyendo en la idea de la mímesis perceptual, aunque Manovich plantea una diferenciación estructural que de alguna forma sigue con la tendencia moderna de otorgarle a la visión una situación de jerarquía perceptual:

Una imagen codificada digitalmente tiene por tanto dos identidades, por decirlo así: una que satisface las demandas de la comunicación humana, y otra que la vuelve adecuada para las prácticas de producción y distribución que se basan en el ordenador (Manovich 2005 p. 243).

La ilusión de la imagen digital se mueve de esta forma más hacia la simulación ya que no sólo busca la apariencia visual correspondiente con la realidad sino que también busca una similitud en la forma en que interactuamos unos con otros (esto involucra el movimiento y la concepción de espacio), cómo sentimos, cómo pensamos y cómo nos comunicamos. Por lo tanto un nueva mímesis, en correspondencia a los nuevos medios y a la realidad social que los produce, involucra directamente aspectos que antes se mantenían subordinados por la hegemonía de la visión y el áurea de la distancia:

De ahí que, en última instancia, la simulación plenamente "realista" de un ser humano [lo que establezco como mímesis perceptual]* requieran sólo lograr por completo el paradigma de la inteligencia artificial original, sino ir más allá de éste, puesto que la inteligencia artificial original perseguía la simulación de la percepción y de los procesos de pensamientos humanos, pero no de la emociones y motivaciones (Manovich 2005 p-244).

Es el conjunto de todas las funciones lo que le confiere una dimensión mimética a la imagen digital y ahora la industria pareciera que se dirige hacia allí. No sólo la visión es necesaria para la simulación, o la mímesis, sino que es necesario que el espectador interactúe con la imagen para que su experiencia cada vez sea, perceptualmente, más completa. La mímesis así, es lo que R. Callois (citado en Sarikartal. en Brea 2005 p. 107) considera como la cesión a la tentación del espacio, que nos compele a fundirnos con él perdiendo así nuestra unidad.

\subsection{La mímesis percetual. Lo háptico como función necesaria.}

Que la vista y el tacto están unidos es una idea que se ha originado desde hace mucho tiempo. La constatación del mundo por los diferentes sentidos es concebida por todas las filosofías y por todas la disciplinas científicas. Sin embargo, la vista como sentido ha tenido también un lugar privilegiado no sólo en la forma en la que estamos en el mundo sino la forma en la que lo conocemos. Así la vista, el ver, se convierte en una epistemología, una epistemología un tanto incompleta, pero la base de la experiencia cognoscitiva. Así lo concibió Platón en su Caverna en donde el sentido de la vista es la herramienta para poder ver la luz y la verdad. Es cierto también que sólo a través de un penoso ascenso (con el cuerpo claro está), es posible salir de las tinieblas en el que se encuentran sólo el reflejo de las cosas. A la visión platónica se le incorpora la visión cartesiana que amplía las capacidades visuales e incorpora las táctiles, aunque el tocar por sí mismo no conlleva más que la confirmación de lo que se ve. Con la inmersión de todo el cuerpo dentro de ambiente virtuales, la percepción que se trata de alcanzar es el intento mimético más fuerte que se ha realizado en la historia, aunque existan manifestaciones que lo hayan hecho anteriormente, como las catedrales, la ópera o el diseño de jardines.

\footnotetext{
*El paréntesis es mío.
} 
En la época anterior al creación de ambientes digitales virtuales envolventes, la arquitectura es la manifestación más cercana en interacción. Es necesaria la incorporación corporal completa para el consumo de la obra. Ningún sentido se queda fuera de la experiencia (en realidad, en ningún momento los sentidos se quedan fuera de la percepción, y sólo los casos que fisiológicamente lo impidan, los sentidos siempre componen la percepción) y tratar de marginar a alguno de ellos siempre resulta en una apuesta difícilmente lograda. Para Benjamin (citado en Sarikatal. p 105. en Brea. 2005), "Las tareas a las que se enfrenta el aparato humano de percepción en el momento de cambio histórico no se pueden resolver por medios ópticos, es decir, sólo a base de contemplación. Se las va controlando gradualmente por el hábito, bajo la dirección de la apropiación táctil”

Aquí la mímesis perceptual sería como la herramienta con la que contamos para aminorar el impacto de la realidad que además da paso a la simbolización que nos vuelve a situar en el mundo ya de una forma protegida. Ahora bien, si la mímesis es en cierta forma una herramienta de protección contra la realidad, ¿cómo puede ser que el ver, la acción que concreta la mímesis, pueda funcionar como una epistemología? Platón vuelve a resonar con fuerza y el reflejo parce engullir nuestras posibilidades de realizar una percepción directa de la realidad. Esto es porque como individuos sociales, siempre accedemos al mundo a través de una mediación culturalmente construida.. Pero al mismo tiempo pertenecemos al mundo, lo que permite encontrar en nosotros mismos un reducto fisi-biológico que nos proporciona una resistencia suficiente para no sumergirnos de lleno en la percepción negándonos la conciencia propia. (Buck Morss citado en Sarikartal. p 105. en Brea 2005). Las capacidades sinestésicas, como la de sentir con los ojos, son parte del sistema que hace conectar los perceptos, los estímulos, con la memoria y en base a esa conexión podemos conformar un lenguaje mimético.

Un lenguaje mimético contiene conciencia de reacciones físicas, cinéticas y sicológicas en relación al manejo sígnico de ellas, como gestos, movimientos, posturas, ademanes, etc. por lo que no se debe entender esta creación del lenguaje mimético como una vuelta a una crítica semiótica de la percepción. Hal Foster(citado en Sarikatal. p 111. en Brea. 2005) lo expresa claramente de esta forma: "... entender la mirada como siempre semiótica es domesticarla antes de tiempo".

La mímesis nos protege porque crea una pantalla construida. La sensibilidad, como Benjamin lo propone, siempre nos conduce hacia fuera de nosotros mismos. Recuerdo que la mímesis la concibo como una percepción completa y no sólo una espejismo visual, aunque los espejismos tienen mucho de sinestesia. Pero retomando la idea de que llevamos un sustrato isomórfico biológico, es la mímesis la que "crea el vínculo visceral que conecta al que percibe con lo percibido" (Taussig citado en Sarikatal. p 107. en Brea. 2005), y es ese vínculo "visceral" el que nos revela que dentro de la ilusión de Gombrich, o el simulacro virtual de la imagen digital de Manovich hay un puente que nos permite unir la representación y lo representado. La posibilidad de ver el mundo de la imágenes, las imágenes del mundo y el mundo mismo.

\subsection{La pantalla como individuo y la pantalla como imagen.}

Al hablar de la pantalla como individuo, lo que trato de decir es que en la percepción espontánea, la pantalla es la manera de hacer patente la conciencia perceptual del individuo. Esto es que, cuando uno es conciente de ser el sujeto que mira, en ese momento se crea una escisión espacio-temporal del mundo en la que nuestra mirada proyecta una compleja relación de aspectos cineticos, sinestésicos, emotivos, semióticos que dirigen nuestra atención hacia algunas cosas y no hacia otras. En la conciencia de saberse visionario hay una pérdida asumida, ya que al centrar la atención en un aspecto del mundo, lo demás se desvanece en una especie de desenfoque generado por la profundidad de campo. Manovich (2005) apunta que el precio que se paga por la conciencia de la visión es una especie de cárcel en la que el espectador debe quedarse quieto, debe inmovilizarse de la misma forma en que se inmovilizan los límites del percepto elegido como objeto de la visión. Los límites de nuestra atención son los que forman la pantalla. Como lo que percibimos ya nos es un todo cambiante fluido sino un extracción perceptual del mundo, podemos entonces crear la representación de ese tajo de mundo que hemos capturado, y que a su vez nos captura nuevamente la mirada. Ese corte es la pantalla. La pantalla que surge desde el sujeto que percibe es en realidad el ejercicio de una decisión de selección que es activa, porque se renueva constantemente; pero una vez que selecciona, debe detenerse para que entonces la imagen pueda surgir.

Un puro segmento recortado que define con claridad los bordes, irreversible e incorruptible; todo lo que le rodea lo hace desaparecer en la nada y queda sin nombre, mientras que todo lo que admite en su campo es promovido a la esencia, a la luz y a la visión (Barthes. c. en Manochic p. 156 2005).

El sujeto perceptor es el que crea la pantalla al seguir el impulso necesario de confirmar su existencia como sujeto. O como Lacan lo propone "el sujeto está determinado por $<<$ un objeto privilegiado, surgido de alguna separación primitiva, alguna automutilación inducida por el acceso mismo de los real»" (Lacan citado en Sarikatal. p 108. en Brea. 2005) . Esta operación compleja que se lleva a cabo de manera continua durante toda nuestra vida la realiza el sentido de la vista, supuestamente. Las artes dióptricas junto a la perspectiva monocular han hecho que la creación de la pantalla recayera predominantemente en el sentido de la vista; además, la idea de la representación de la realidad aislada por los lados de la pantalla se ha construido como una lámina delgada que reduce las interacciones de otros sentidos y otras operaciones significantes. Sin embargo como hemos ido planteando a lo largo de este ensayo, la vista por sí misma no es capaz de realizar esta acción. La mirada por sí sola no puede congelar el movimiento. Las fotografías de Marey y el cine son una pruebas de ello. Nuestra mirada no descompone el flujo espacio temporal en escenas delimitadas sin la confirmación corporal. Detener el movimiento es básicamente una operación cinética del cuerpo, por eso cuando vemos el cine o la 
televisión debemos inmovilizarnos. Si pensamos en la visión natural como "un trenzado y un anidamiento de lo óptico y lo táctil" (Mitchell. p. 23 c. en Brea. 2005), las representaciones surgidas de esa visión estarán estructuradas bajo ese anidamiento. Por lo tanto, cuando hablo de la construcción de la pantalla asumo que se pone en marcha perceptualmente una serie de relaciones complejas entre sentidos, significantes, signos, pensamientos, emociones, capacidades, construcciones sociales e individuales. La omnivisión nos permite atacar un problema complejísimo reduciéndolo a escalas manejables y tangibles. Sin embargo no se debe olvidar que el reduccionismo puede reducir las posibilidades de entender si acaso algunas de estas maravillosas relaciones.

Creo que es eso lo que Lacan expone cuando dice que el sujeto, como punto de arranque de la mirada, se confunde con el espacio (Lacan citado en Sarikatal. p 108. en Brea. 2005) y como he dicho anteriormente, no es posible disolverse en el espacio sin estar conciente de la corporalidad. Así, la creación de la pantalla como origen de la representación es un acto de corporalidad de naturaleza diferente a la concepción del espacio geométrico. Sólo es posible la tactilidad de la mirada si en el acto de la representación está incluido de manera estructural, los elementos que sirvan de referencia para la disolución sin perder la conciencia de ser el que ve.

La mímesis perceptual es, entonces, ya no una búsqueda sino una consecuencia. La mirada y el cuerpo cortan un espaciotiempo, con ese corte podemos generar signos. El corte en sí mismo ya es un signo. Ese corte se realiza a través de trasladar a una pantalla generada desde el sujeto, la percepción del mundo. Este corte debe ser coincidente, como un molde en positivo. En ese molde, en el que luego se vaciará la representación, ya funciona la complejidad del precepto, por lo que al vaciar la representación, ésta contendrá esa complejidad a manera de estructura. Siguiendo a Lacan de la mano de Sarikatal, el camuflaje como efecto de la mímesis perceptual, sitúa al sujeto dentro de la pantalla y no sólo como el sujeto que la construye. La mímesis perceptual es entonces, "insertarse en una función cuyo ejercicio le prende" (Lacan citado en Sarikatal. p 108. en Brea. 2005).

Cuando el sujeto es parte de la pantalla de la representación vive una paradoja, ya que por un lado se ha desvanecido en la función que le ha prendido, pero en su estado de mímesis sigue siendo un sujeto perceptor porque su conciencia sigue funcionando como la base de la mímesis. Si decide cambiar de pantalla entonce dejará de mimetizarse, volverá a consolidarse como un ser que está en pos de una nueva percepción y tal vez de una nueva representación "<<el sujeto intenta acomodarse a esa mirada, se convierte en ese punto puntiforme, ese punto desvaneciente con el que el sujeto confunde su propio desfallecimiento >>" (Lacan citado en Sarikatal. $p$ 108. en Brea. 2005).

Así, el sujeto mantiene una cordura de la realidad a partir de un ejercicio mimético de ella en el que por una parte de funde y por otra se separa a través de una confirmación conciente, a partir de la representación. Es entonces cuando La pantalla perceptual funciona como pantalla de representación, cuando la pantalla es una imagen. Antes de eso, el sujeto era parte de la pantalla porque no solo era un observador, sino que formaba parte de esa misma pantalla, se fundía perceptualmente con la realidad:

Sugiero que la oscilación de lo imaginario adquiere un nuevo carácter en este estadio de la mímesis prerracional. Aunque todavía no sea posible la formación de símbolos, se puede observar que lo imaginario se aleja del cuerpo pantalla en forma de desdoblamiento, para poder jugar entre los dos. Sólo después de este juego en división, el imaginario es capaz de aliarse con lo simbólico para formar una Gestalt del objeto por un lado, e identificar una imagen del ser por el otro. (Sarikatal. p 112. en Brea. 2005).

Foster recuerda que en este estadio, el sujeto funciona como una mancha antes que como una imagen, una mancha opaca que impide el paso de la luz y que oblitera el campo visual desde diferentes punto.

Cuando una mirada se hace consciente, cuando a través de una percepción mimética se genera una afirmación del sujeto por medio de una representación, entonces surge la imagen pantalla. La pantalla así es la consolidación de la percepción del sujeto en donde esa percepción estructura la imagen pantalla de la misma forma en la que se encuentra estructurado el sujeto pantalla. De ahí que la mímesis perceptual sea una consecuencia. La imagen pantalla ya nos es la etapa mimética prerracional, la racionalidad ya está presente lo que permite la simbolización que se relaciona con la subvocalización y por lo tanto con el habla y el sonido, la iconización y sus grados que mantiene una relación estrecha con la abstracción del espacio y del tiempo, la indexación con sus niveles que se relaciona con el grado perseguido de tactilidad y cinestesia. Así, a partir de esta afirmación, la observación de una imagen, ya sea un cuadro, una fotografía o una imagen digital en la pantalla del ordenador, es aceptar la percepción mimética de otro, es un encuentro en el que uno cede ante la mirada del otro. Esto significa que el sujeto pantalla, se disuelve en la imagen pantalla de otro, aunque no sin oponer resistencia. La mímesis en su sentido aristotélico (lo mejor con lo más bello) es el señuelo para bajar nuestra mirada en pos de la del otro. Cuando aceptamos esa mirada, y eso quiere decir, aceptar mirar como el otro, la resistencia cede. El equilibrio vuelve a ser el que nos mantienen como sujetos concientes de nuestra mirada en este mundo lleno de afirmaciones de lo que es lo real:

Una vez que la pantalla se coloca en el punto adecuado, donde mejor se ve la imagen, el espectador puede retirarse a su antiguo lugar como sujeto de representación. La violenta batalla o el $<<$ teatro de la crueldad $>$, en términos de Antonin Artaud (1958), acaba de espectáculo aristotélico. Las dos partes, artista y espectador, deponen las armas en señal de paz. Sin embargo, la paz tiene un precio para las dos partes, ya que ninguna de ellas habrá logrado una victoria total. El objetivo real de sus deseos, o mejor dicho, $<<l o$ real > en sí, también se representa como algo que se sitúa tras $<<l a ~ p a n t a l l a \gg>$, -algo inasimilable en la representación, pero imaginable 
más alla de ella-. La satisfacción puede consumarse como <<placer >> en base a un contrato establecido entre las dos partes, pero siempre con un sentimiento de ausencia. (Sarikatal. p 111. en Brea. 2005).

El mundo no se encuentra en las ilusiones ni en las simulaciones; nuestra percepción lo sabe, nuestro cuerpo lo sabe. Hay algo, o mucho, de ausencia en la imagen. La imagen pantalla nos protege de aquello que anhelamos. El mundo sólo se obtiene perteneciendo a él, y ninguna pantalla puede ofrecernos esa pertenencia. Si en el mito de Narciso existe un momento de pura desesperanza es cuando las manos y los brazos de Narciso recogen el agua, que en ese momento no es agua, ni espejo sino corporalidad fluida, tangible pero insostenible, inasible. Una pérdida sin fin, una imagen que devora a su imaginante, un desvanecimiento que certifica que la estructura de la pantalla está soldada con la ausencia.

\section{FUENTES REFERENCIALES}

AGUES DA CRUZ SILVA, Salif Diallo. Do paradigma do ver ao do tocar. O devenir háptico na criaçao artística contemporânea. Directores Francisco Berenguer Francés, Joaquim Antero Magalhães Ferreira. Tesis doctoral inédita. Universidad Politécnica de Valencia. Facultad de Bellas Artes 20.15

ALCALÁ, José Ramón. La piel de la imagen. Ensayos sobre gráfica en la cultura digital. Sendemá. Valencia 2011

FONTCUBERTA, Joan. La cámara de Pandora. La fotografía después de la fotografía. Gustavo Gili. Barcelona 2010.

HOYAS Frontera, Gema. Percepción táctil e interactividad en la creación artística de realidades virtuales. https://www.upv.es/intermedia/pages/laboratori/grup investigacio/textos/docs/gema hoyas percepcion tactil.PDF

MANOVICH, Lev. El lenguaje de los nuevos medios de comunicación. Paidos. Barcelona 2005.

MARCHAN Fiz, Simón. Las artes ante la cultura visual. Notas para una genealogíaa en la penumbra. En BREA, J.L. Estudios visuales. La epistemología de la visualidad en la era de la globalización. Akal. Madrid 2005.

MITCHELL, W.J.T. Mostrando el ver. Una crítica de la cultura visual. En Estudios Visuales. n\# 1. CENDEAC. Diciembre 2003. Disponible en: http://www.estudiosvisuales.net/revista/pdf/num1/mitchell.pdf Consulta el 29-04-2015.

MITCHELL, W.J.T. No existen medios visuales. En BREA. J.L. Estudios Visuales. La epistemología de la visualidad en la era de la globalización. Akal. Madrid 2005.

PLATÓN, "La República", en Platón, Diálogos, Madrid, Gredos, 2011, p. 222, 514a

SARIKATAL Çetin. Shock, mirada y mímesis. La posibilidad de un enfoque preformativo sobre la visibilidad. En BREA, J.L. Estudios visuales. La epistemología de la visualidad en la era de la globalización. Akal. Madrid 2005. 